\title{
“TOLERANCIA CERO”, UN EXPERIMENTO-ESPECTÁCULO GESTADO POR JUANA ESCABIAS
}

\author{
"TOLERANCIA CERO", A PERFORMANCE-EXPERIMENT ORGANIZED BY JUANA \\ ESCABIAS
}

Juana Escabias

Dramaturga y directora de escena

\section{Resumen:}

El 25 de noviembre del 2013, coincidiendo con el Día Internacional de la Erradicación de la Violencia contra las Mujeres (decretado por la ONU décadas atrás) en el Teatro La Jaramilla, de Coslada (Madrid-ESPAÑA) se exhibió públicamente un original espectáculo teatral. Su título era "Tolerancia Cero", en alusión a la necesaria movilización de la sociedad española para erradicar la violencia de género entre las parejas. No era un espectáculo teatral "al uso", sino un experimento en toda regla organizado por la dramaturga y directora de escena Juana Escabias, asistida por la actriz y también directora de escena Adriana González Borgas. El elenco actoral no estuvo formado por actrices profesionales, sino por mujeres que luchan contra la lacra de los malos tratos (incluidas algunas de las víctimas de esa lacra social).

\section{Palabras clave:}

espectáculo, malos tratos, víctimas

\section{Abstract:}

On November 25, 2013, coinciding with the International Day for the Eradication of Violence against Women (decreed by the UN decades ago) at the La Jaramilla Theater, in Coslada (Madrid-SPAIN) an original theatrical show was publicly exhibited. Its title was "Zero Tolerance", alluding to the necessary mobilization of Spanish society to eradicate gender violence between couples. It was not a "regular" theater show, but a full-fledged experiment organized by the playwright and stage director Juana Escabias, assisted by the actress and also stage director Adriana González Borgas. The cast was not made up of professional actresses, but rather women who fight against the scourge of abuse (including some of the victims of this social scourge).

\section{KeYWORDS:}

show, mistreatment, victims 
El 25 de noviembre del pasado año, coincidiendo con el Día Internacional de la Erradicación de la Violencia contra las Mujeres (decretado por la ONU décadas atrás) en el Teatro La Jaramilla, de Coslada (Madrid-ESPAÑA) se exhibió públicamente un original espectáculo teatral. Su título era "Tolerancia Cero", en alusión a la necesaria movilización de la sociedad española para erradicar la violencia de género entre las parejas. No era un espectáculo teatral "al uso", sino un experimento en toda regla organizado por la dramaturga y directora de escena Juana Escabias, asistida por la actriz y también directora de escena Adriana González Borgas. El elenco actoral no estuvo formado por actrices profesionales, sino por mujeres que luchan contra la lacra de los malos tratos (incluidas algunas de las víctimas de esa lacra social).

La motivación del espectáculo se encontraba en las alarmantes cifras de asesinatos de mujeres a manos de sus parejas que vienen registrándose en España desde hace unas décadas (entre sesenta y setenta al año). Sus promotores fueron los responsables del CIDAM (Centro de Información, Documentación y Asesoramiento a la Mujer), concretamente su directora, Teresa Zurita. Desde hace años, el CIDAM sirve como centro de referencia para la lucha contra la violencia ejercida contra las mujeres. Este centro se encuentra en Coslada, población del cinturón industrial de Madrid muy cercana al aeropuerto de Bajaras y cuya población se dedica fundamentalmente al sector servicios. En Coslada, muy castigada por el desempleo, el CIDAM atiende a las mujeres que sufren emergencias relacionadas con la violencia de género a través de equipos médicos, psicológicos, jurídicos y sociales. Al mismo tiempo realiza una tarea de prevención, ofreciendo a las mujeres de la localidad numerosos talleres a los que pueden asistir de forma gratuita. Las clases son de una gran diversidad: orientación para el empleo, informática, actividades físicas y culturales, etc... En todas ellas, el género se imparte como enseñanza transversal, para concienciar a las mujeres acerca de sus derechos, posibilidades de crecimiento personal y autorealización, y como marco para el aprendizaje de fórmulas de convivencia en igualdad que permitan a las mujeres la adquisición de una mayor proyección pública y social en contraposición a la tendencia social y cultural de mantenerlas enclaustradas en sus casas.

Uno de los talleres impartidos en el CIDAM desde hace años se denomina "Creación en femenino". Dentro de él, un grupo de treinta mujeres de entre treinta y sesenta y cinco años (guiadas por un monitor) escribían ficción (relatos y poesía fundamentalmente), como herramienta terapéutica para luchar contra la violencia de género. Teresa Zurita, la ya mencionada directora del CIDAM, le lanzó una propuesta a Juana Escabias, utilizar a aquel grupo de mujeres para montar un espectáculo teatral en el que se trabajaría durante todo un curso, y finalmente se exhibiría públicamente en un teatro. Así empezó a gestarse "el experimento". 
El primer paso fue hablar con las alumnas y lanzarles la propuesta, que todas aceptaron encantadas. Algunas manifestaron su temor a actuar frente a un público formado por extraños (la entrada al teatro sería libre y gratuita), pero esa reticencias de los primeros días pronto acabaron venciéndose. El segundo paso fue implicar en el proyecto a la actriz y directora escénica Adriana González-Borgas, cuya misión sería adiestrar escénicamente a las improvisadas actrices, haciendo cargo de impartir semanalmente clases de voz-dicción-proyección-articulación, expresión corporal y movimiento escénico, interpretación, etc... El tercer paso fue la creación de la propuesta textual que articularía el espectáculo, un guion temático del que se ocupó Juana Escabias. Se reunió a las alumnas y se compartió con ellas la propuesta.

La propuesta, a groso modo, fue la siguiente: se eligió a una de ellas que haría el papel de mujer maltratada, de víctima. Para el resto se estableció que cada una de ellas interpretaría un personaje actante que interviniera de modo profesional-casual-social en el proceso de los malos tratos hacia la mujer. El abanico de posibilidades era grande, podían ser familiares de una víctima (madre, padre, hermana, suegro, suegro, hija, hijo, cuñados, cuñadas...), vecinos o compañeros de trabajo, médicos ante los que se presentara una víctima, policías ante quienes alguna mujer interpusiera una denuncia, jueces y abogados encargados de la defensa o la acusación, periodistas encargados de dar eco a esos incidentes, etc, etc, etc. Cuando todas tuvieron su papel y el abanico de posibilidades estaba cubierto se les pidió que comenzaran a escribir su propio papel. La premisa fue que la obra estaría dividida en dos grandes bloques, antes de y después de. En la primera parte (antes de), cada uno de los actantes debía presenciar cómo se maltrataba a la víctima, y todos ellos (por acción u omisión) participarían en el maltrato, negando ayuda a la víctima y aislándola hasta que ella muriera. En la segunda parte, la ficción volvía atrás, a la víctima se le daba una segunda oportunidad, y cada uno de los actantes volvía a representar su papel, pero en esta ocasión eran familiares o vecinos solidarios, médicos que ayudaban a la víctima, jueces o abogados que la ponían a salvo. De ese modo, a través de todo un mecanismo de simbolismo escénico, la víctima "resucitaba", regresaba a la vida gracias a la ayuda y apoyo de todo el elenco actoral.

Desde el primer momento surgieron protestas porque las alumnas se negaron "a hacer de malas" y a perjudicar a una mujer maltratada ni siquiera en la ficción. Hubo que emplearse a fondo para convencerlas de que para denunciar la situación y mostrársela al público, era más efectivo tratarla con la crudeza que ella misma se manifiesta en la realidad. Superado ese rechazo lo demás fue trabajo duro, escritura y reescritura de textos, acomodación de papeles y adecuación del material literario a una forma dramática. Se diseñó el espectáculo (escenografía, luces, sonido, etc) y comenzaron los ensayos. Imprescindible que cada une memorice su papel. A esas alturas ya se contaba con un alumno voluntario, vinculado al propio CIDAM, que 
se ofreció a realizar el personaje de maltratador. En varias ocasiones, en las clasesensayos, alguna de las mujeres rompía a llorar, recordando los malos tratos padecidos en su persona en el pasado.

La exhibición del espectáculo fue una extraordinaria terapia de aprendizaje para las mujeres, y una auténtica catarsis colectiva para el público asistente. Sentados en el graderío se encontraban nuevas víctimas de la violencia de género que en el debate organizado tras el espectáculo se atrevían a hablar sin vergüenza ni reparos, hijos e hijas de las víctimas, policías especializados en maltrato y otros profesionales relacionados con esa lacra que expresaron ante todos sus emociones y opiniones sobre el mismo. Se puso de manifiesto que el teatro es una extraordinaria escuela de ciudadanía que a través de la mostración de comportamientos y modelos ejemplarizantes.

\section{BIBLIOGAFÍA}

Escabias, J. (2011). Tragedia y comedia en el teatro español actual. Signa: Revista de la Asociación Española de Semiótica, (20), 625-628.

Escabias, J. (2014). “ Tolerancia cero”, un experimento-espectáculo gestado por Juana Escabias. Revista Internacional de Culturas y Literaturas, 15.

Escabias, J. (2014). Malas y más que malas, por supuesto: breve alegato sobre la necesidad de ir a contracorriente. In Malas (pp. 219-228). Universidad Nacional de Educación a Distancia-UNED.

Clavijo, M. M. (2014). Entrevista a Juana Escabias, dramaturga y directora de escena. RAUDEM. Revista de Estudios de las Mujeres, 2, 305-322. 